\title{
Management of Ganglion: Comparative Study between Surgical Excision and Aspiration followed by Intralesional Steroid Injection
}

\author{
Uddin $\mathrm{MN}^{1}$, Rahman $\mathrm{MMM}^{2}$, Rahman $\mathrm{MM}^{3}$, Hossain SMS ${ }^{4}$
}

DOI: https://doi.org/10.3329/jafmc.v14i2.45907

\begin{abstract}
Introduction: Ganglions are tense, smooth, cystic transilluminant swellings. They are the commonest soft tissue swelling of the hand and most commonly found on the dorsum of the wrist. At present aspiration or surgery are the management options of Ganglion. To improve the outcome of treatment some advocated aspiration combined with steroid injection into the cyst.
\end{abstract}

Objectives: To compare pain relief, cosmetic results and recurrence rate in the management of ganglion with aspiration followed by intralesional steroid (triamcinolone acetate) injection and surgical excision.

Materials and Methods: Prospective interventional control trial was performed from October 2016 to October 2017. Fifty patients were treated in two groups in group A (33 patients), aspiration followed by intralesional steroid (triamcinolone acetate) injection and group B (17 patients) surgical excision was performed on. Follow up of patients were done on at one, three and six months after treatment up to 1 year.

Results: In group A out of 33 patients, pain relief was in all $33(100 \%)$ patients, there was no scar mark and only in 4 $(12.12 \%)$ patients there was recurrence which was managed by repeating the procedure. In group B, out of 17 patients, pain relief was in $15(88.23 \%), 17(100 \%)$ patients had linear scar mark, $1(5.8 \%)$ patient had hypertrophic scar and $02(11.76 \%)$ patients had recurrence which was managed with intralesional steroid as group $A$.

Key-words: Dorsal wrist ganglion, Triamcinolone acetate, Intralesional steroid, Excision.

\section{Introduction}

Ganglions are the most common tumour like conditions in the hand and wrist which usually arise from tendon sheath or joint capsule ${ }^{1,2}$. Histologically ganglion is a benign cyst and has a thin connective tissue capsule, formed by compressed stroma, but without synovial lining, and contain mucinous materia|3,4. More common in females in age group of 20 to 40 years. Patients are usually worried about mass and pain in wrist. Despite its benign nature, a ganglion can be problematic. A significant number of patients with ganglion consult with their doctor or the surgeon, complaining of pain. A great number of patients are concerned about the cosmetic appearance.

These cysts do not have an epithelial lining and are therefore pseudocysts. The main aim of treatment is to reduce the production of the gelatinous substance contained within it, rather than excision of the cyst. Various procedures have conventionally been used to treat a ganglion cyst, namely, watchful wait, aspiration of the cyst, injection of intralesional sclerosant into the cyst and finally surgical excision of the cyst (including debridement of the joint capsule). Surgery requires meticulous excision of the whole ganglion complex to prevent recurrence while protecting the adjacent tendon pulleys and neurovascular bundles. Unfortunately, all of these procedures have high recurrence rates due to remnant tissue resulting from inadequate excision ${ }^{2}$. This study was done to compare the effectiveness of the two traditional methods aspiration followed by intralesional steroid (triamcinolone acetate) injection and surgical excision.

\section{Materials and Methods}

This prospective interventional control trial was carried out at Department of Surgery, Combined Military Hospital, Rangpur between October 2016 to October 2017. Patients with clinical diagnosis of ganglion and not treated before for the same were included in the study. Diagnosis of ganglion was based on history and clinical examination. All patients were informed and explained about the lesion and their treatment plan. Patients were allowed to choose their treatment plan and were accordingly put into respective group. Patients were treated in two groups; group A, Aspiration followed by intralesional steroid (triamcinolone acetate) injection and group $B$, surgical excision. In group $\mathrm{A}$, under standard aseptic precautions, was done using $18 \mathrm{G}$ needle and $40 \mathrm{mg}$ triamcinolone acetate was injected using the same needle port and pre-filled syringe containing the diluted triamcinolone. A firm bandage was applied and wrist immobilized for 24 hours. In group B the surgical excision was done using similar standard aseptic precautions and after local infiltration of $2 \%$ xylocaine. In surgical procedure entire cyst complex including cyst, pedicle was excised. A follow-up visit was at one, three and six

1. Lt Col Md Nasir Uddin, MBBS, FCPS, Classified Specialist in Surgery, CMH, Rangpur \& Head of the Department of Surgery, Rangpur Army Medical College (E-mail: nasir9631@gmail.com) 2. Maj Gen Munshi Md Mojibur Rahman, MBBS, FCPS, Ex-DGMS, Bangladesh Armed Forces 3. Maj Gen Md Mahbubur Rahman, MBBS, FCPS, Consultant Surgeon General of Bangladesh Armed Forces 4. Col SM Shakhwat Hossain, MBBS, FCPS, Classified Surgical Specialist and Hepatobiliary Surgeon, CMH, Dhaka. 
months after treatment. Success was defined as relief in pain, disappearance of the cyst at final visit and scarless treatment. In case of recurrence treatment was defined as failure.

\section{Results}

A total of 50 patients were included in the study and among them, $37(74 \%)$ were females and $13(26 \%)$ males. Mean age was 24.7 \pm 7.69 (Range-14-50) years. Group A comprised of $26(78.7 \%)$ females and 7(21.2\%) males. Group B comprised of $13(76.4 \%)$ females and $4(23.5 \%)$ males. With respect to age, sex and side of the lesion no significant difference was seen between two groups (Table-I). Swelling was a common presentation in all the subjects, pain and discomfort 39(78\%), cosmetic $27(54.85 \%$ ) and apprehension of tumour $23(46 \%)$ (Table-II). The pain was relieved in all $33(100 \%)$ patients of Group A with aspiration followed by intralesional triamcinolone with no scar formation. On the contrary, only 15 (88.23\%) patients pain subsided after surgical excision, all 17 (100\%) of patients were left with scar at the site of surgery and among them 2.6\% had hypertrophic scar (Table-III). Among Group A patients, $29(87.87 \%)$ cases were successful with $4(12.12 \%)$ recurrences. Group B patients had $15(88.23 \%)$ success with $02(11.76 \%)$ recurrences (Table-IV).

Table-I: Distribution of patients according to sex and Groups $(n=50)$

\begin{tabular}{|l|l|c|c|c|}
\hline \multirow{2}{*}{\multicolumn{2}{|c|}{ Characteristics }} & \multicolumn{1}{|c|}{ Group-A } & Group-B & \multirow{2}{*}{ Total } \\
\cline { 3 - 4 } \multicolumn{2}{c|}{} & $\begin{array}{c}\text { Frequency } \\
(\%)\end{array}$ & $\begin{array}{c}\text { Frequency } \\
(\%)\end{array}$ & \\
\hline Sex & Female & $26(78.7)$ & $7(21.2)$ & $37(74)$ \\
\hline & Male & $13(76.4)$ & $4(23.5)$ & $13(26)$ \\
\hline Age & \multicolumn{2}{|c|}{ Mean \pm SD: $24.7 \pm 7.69 ;$ Range-14-50 } \\
\hline
\end{tabular}

Table-Il: Finding symptoms of the diseases in patients $(n=50)$ *

\begin{tabular}{|l|c|c|}
\hline \multicolumn{1}{|c|}{ Symptom } & No of patients & Percentage \\
\hline Swelling & 50 & 100 \\
\hline Pain and Discomfort & 39 & 78 \\
\hline Cosmetic & 27 & 54 \\
\hline Apprehension of tumour & 23 & 46 \\
\hline
\end{tabular}

*Multiple presentations

Table-III: Response of treatment Group A $(n=33)$ and Group $B(n=17)$

\begin{tabular}{|l|l|c|c|}
\hline \multicolumn{2}{|c|}{ Response of Patients } & Group-A n(\%) & Group-B n(\%) \\
\hline \multirow{2}{*}{ Pain } & Pain Relief & $33(100)$ & $15(88.2)$ \\
\cline { 2 - 4 } & No Relief & 0 & $02(11.8)$ \\
\hline \multirow{2}{*}{ Cosmetic value } & Scar present & 0 & $17(100)$ \\
\cline { 2 - 4 } & No scar mark & $33(100)$ & 0 \\
\hline
\end{tabular}

Table-IV: Distribution of patients according to treatment outcome

\begin{tabular}{|l|c|c|}
\hline \multicolumn{1}{|c|}{ Treatment } & Group A n(\%) & Group B n(\%) \\
\hline Success rate & $29(87.9)$ & $15(88.2)$ \\
\hline Recurrence rate & $4(12.1)$ & $2(11.8)$ \\
\hline
\end{tabular}

\section{Discussion}

A ganglion is a benign condition mainly of wristregion. Females of 20 to $40 \mathrm{yrs}$ are commonly affected. As it is always visible to the patient, it makes them worried for any malignancy. Benign course and spontaneous resolution in 30\% to $40 \%$ of cases. Variety of non-operative methods are used to treat ganglion. These include watchful wait and re-assurance, aspiration, sclerotherapy, aspiration with intralesional steroid injection, and surgical excision. Recurrence is the most common complication of treatment of ganglions. Humail SM et al reported the recurrence rate $43 \%$ in aspiration and intralesional steroid injection and $24 \%$ in surgical excision for treatment of dorsal wrist ganglions ${ }^{5}$. Limphayan et at in their study on 24 patients with wrist ganglion, reported that the success rate by aspiration combined with methyl prednisolone acetate injection was $38.4 \%$, and by excision was $81.8 \%{ }^{6}$. Paramhans et al compared two methods of aspiration followed by triamcinolone injection and surgical excision for treatment of ganglions. They found a recurrence rate of $8.4 \%$ and $21.5 \%$ respectively and concluded that intracystic steroid injection was a safe mode of treatment ${ }^{7,8}$. Different Studies for treatment of ganglia with aspiration only showed success rates of $33 \%, 60 \%$ and $27 \%$, while in this study the success rates were much higher owing to the injection of triamcinolone acetonide in addition to aspiration $^{9,10,11}$.

In this study, three aspects of treatment were compared; one is relief in pain which we found $100 \%$ after aspiration followed by steroid injection, but after surgical excision, $11.76 \%$ still complained of pain/ discomfort. The second aspect of this study was cosmetic result, which shows no scar mark with aspiration followed by steroid injection, but after surgical excision patient had linear scar mark over wrist joint \& in 1 (5.8\%) had hypertrophic scar. Thirdly, $12.12 \%$ patients had recurrence with aspiration followed by steroid injection while $11.76 \%$ recurrence was found after surgical excision.

\section{Conclusion}

Triamcinolone acetate is a novel sclerotherapeutic agent used for the treatment of ganglion by intralesional route. So aspiration and Intralesional injection of triamcinolone acetate may be considered a simple, safe, convenient, cost-effective and less-invasive alternative to surgical excision for the treatment of ganglion.

\section{References}

1. Nelson CL, Sawmiller S, Phalen GS. Ganglions of the wrist and hand. JBJS 1972; 54(7):1459-64.

2. Plate AM, Lee SJ, Steiner G, Posner MA. Tumorlike lesions and benign tumors of the hand and wrist. JAAOS 2003; 11(2):129-41. 
3. Gude W, Morelli V. Ganglion cysts of the wrist: Pathophysiology, clinical picture, and management. Current reviews in musculoskeletal medicine 2008; 1(3-4):205-11.

4. Nahra ME, Bucchieri JS. Ganglion cysts and other tumor related conditions of the hand and wrist. Hand Clinics 2004; 20(3):249-60.

5. Humail SM, Abidi AR, Naeem UI Haq S et al. Comparative study of two methods for treatment of dorsal wrist ganglion. J Pak Orthop Assoc 2010; 22(1):53-7.

6. Limpaphayom N, Wilairatana V. Randomized controlled trial between surgery and aspiration combined with methylprednisolone acetate injection plus wrist immobilization in the treatment of dorsal carpal ganglion. J Med Assoc Thai 2004; 87(12):1513-7.
7. Paramhans D, Nayak D, Mathur RK et al. Double dart technique of instillation of triamcinolone in ganglion over the wrist. Journal of Cutaneous and Aesthetic Surgery 2010; 3(1):29.

8. Rathod CM, Nemade AS, Badole CM. Treatment of dorsal wrist ganglia by transfixation technique. Niger J Clin Pract 2011; 14: 445-8.

9. Varley GW, Needoff M, Davis TR et al. Conservative management of wrist ganglia. Aspiration versus steroid infiltration. J Hand $\mathrm{Surg} \mathrm{Br}$ 1997; 22:636-7.

10. Holm PC, Pandey SD. Treatment of ganglia of the hand and wrist with aspiration and injection of hydrocortisone. Hand 1973; 5:63-8.

11. Derbyshire RC. Observation on the treatment of ganglia. Am J Surg 1966; 112:635-6. 